УДК 81.1.

DOI 10.18413/2712-7451-2020-39-3-477-486

\title{
Директивные речевые акты предписания (разрешения) и запрета в религиозном дискурсе
}

\author{
Омельченко О.В. \\ Волгоградский экономико-технический колледж, \\ Россия, 400007, г. Волгоград, пр. Металлургов, д.17 \\ E-mail: novikova-ok@mail.ru
}

\begin{abstract}
Аннотация. Современный уровень развития лингвистической науки требует совмещения различных лингвистических парадигм и обнаруживает отсутствие дынных о функционировании различных речевых актов в разных типах дискурса - что определяет актуальность данного исследования. Цель исследования - проведение комплексного анализа религиозных предписаний и запретов, построение типологии и определение особенностей религиозных предписаний и запретов. В результате определена специфика религиозных предписаний и запретов (влияние на их построение и содержательное наполнение общей дидактической направленности религиозного дискурса); установлены характеристики предписаний и запретов (четкая адресатная направленность, эксплицитность), которые определяются сферой функционирования религиозный дискурс; выделены основные типы религиозных предписаний (побуждающие, рекомендательные, разрешающие, обещающие) и запретов (предписания, инструкции, объяснения, требования, просьбы). Впервые установлена специфика речевых актов предписаний и запретов, функционирующих в религиозном дискурсе, выявлены структурно-семантические модели религиозных предписаний и запретов, определены их типы.
\end{abstract}

Ключевые слова: каузация действия, социальная норма, условия успешности, религиозная норма, запреты-законы, запреты-предписания, запреты-инструкции, запреты-объяснения, запретытребования, запреты-просьбы.

Для цитирования: Омельченко О.В. 2020. Директивные речевые акты предписания (разрешения) и запрета в религиозном дискурсе. Вопросы журналистики, педагогики, языкознания, 39 (3): $477-$ 486. DOI 10.18413/2712-7451-2020-39-3-477-486

\section{Directive speech acts of prescreptions (permissions) and prohibitions in religious discourse}

\author{
Oksana V. Omelchenko \\ Volgograd State College of Economics and Technique, \\ 17 Metallurgy Av., Volgograd, 400007, Russia \\ E-mail:novikova-ok@mail.ru
}

\begin{abstract}
The current level of development of linguistic science requires the combination of different linguistic paradigms and reveals the lack of information about the functioning of various speech acts in different types of discourse-which determines the relevance of this study. The purpose of the research is to conduct a comprehensive analysis of religious prescriptions and prohibitions, build a typology and determine the features of religious prescriptions and prohibitions. The result of the specificity of the religious injunctions and prohibitions (the influence on their building and contents General didactic orientation religious discourse); the characteristics of the requirements and prohibitions (clear adresata
\end{abstract}


orientation, explicitness), which are determined by the functioning of religious discourse; the basic types of religious prescriptions (encouraging, Advisory, permissive, promising) and restrictions (regulations, instructions, explanations, demands, requests). For the first time, the specificity of speech acts of prescriptions and prohibitions functioning in religious discourse is established, structural and semantic models of religious prescriptions and prohibitions are identified, and their types are determined.

Keywords: causation of action, social norm, success conditions, religious norm, prohibition-laws, prohibitions-prescriptions, prohibitions-instructions, prohibitions-explanations, prohibitionsrequirements, prohibitions-requests.

For citation: Omelchenko O.V. 2020. Directive speech acts of prescreptions (permissions) and prohibitions in religious discourse. Issues in Journalism, Education, Linguistics, 39 (3): 477-486 (in Russian). DOI 10.18413/2712-7451-2020-39-3-477-486

\section{Введение}

Исследование различных типов дискурса, их характеристик и составляющих компонентов стало неотъемлемой частью и одним из приоритетных направлений современной лингвистики. Исследуются характеристики, жанры, стратегии развития, ценности различных типов дискурса. Вместе с тем, несмотря на длительную историю рассмотрения, продолжает оставаться актуальным исследование различных типов и компонентов речевых актов. На фоне большого количества исследований как в рамках дискурсивной лингвистики, так и в рамках теории речевых актов, особенности функционирования речевых актов в конкретном типе дискурса продолжают оставаться малоизученными. В частности, не подвергались рассмотрению речевые акты, функционирующие в религиозном дискурсе. Проблемы речеактовой специфики дискурса до последнего времени не находила своего отражения в публикациях авторов, работающих как в рамках дискурсологии (Н.Б. Мечковская [1994], А.Д. Шмелев [2004] и др), так и в рамках теории речевых актов (Н.Д. Арутюнова [1999], В.Б. Гудкова [2003] и др).

Автором представлено исследование, проведенного для того, чтобы выявить типологию и особенности функционирования директивных речевых актов предписаний (разрешений) и запретов в рамках религиозного дискурса. В качестве гипотезы исследования выдвигаются следующие положения: выступая разновидностью директивных речевых актов, религиозные предписания (разрешения) и запреты реализуются в различных структурно-семантических моделях, демонстрируют специфические черты и представлены рядом четко отличающихся типов в религиозном дискурсе, что определяет их специфику в рамках рассматриваемого типа общения; предписание (разрешение) и запрет, выступая разновидностью директивных речевых актов, составляют сущностную характеристику религиозного дискурса (в силу эксплицитности выражения и общей дидактической направленности данного типа общения).

В первом разделе раскрыта нормативная специфика религиозных предписаний (разрешений) и запретов, определено соотношение религиозных предписаний (разрешений) и запретов с понятиями норма; раскрыто понятие религиозной нормы. Во втором и третьем разделе раскрывается специфика и выстраивается типология религиозных предписаний (разрешений) и запретов.

Материалом исследования послужили текстовые фрагменты религиозного дискурса (текст Священного Писания: Книги Ветхого и Нового Завета), содержащие примеры реализации директивных речевых актов предписаний (разрешений) и запретов. При проведении исследования использовались методы понятийного, интерпретативного и контекстуального анализа. 
Теоретической базой исследования послужили работы Е.В. Аверьяновой [2015], Е.И. Беляевой [1988], Л.М. Бикбаевой [2008], Е.В. Бобыревой [2007], В.И. Карасика [2002], А.И. Изитова [1998], Т.В. Руссиновой [2006], И.Б. Шатуновского [2000] и др.

\section{Нормативная специфика предписаний (разрешений) и запретов}

Директивные речевые акты (к которым относятся предписания и запреты) представляют собой «выражение волеизъявления говорящего, направленное на каузацию деятельности адресата» [Skinner, 1957, с. 78]. Цель адресанта - побудить адресата совершить желаемое действие или остановить (предотвратить) действие, которое представляется адресанту нежелательным. Таким образом, предписания (разрешения) и запреты связаны непосредственно с волей адресанта. Кроме того, в ряде случаев речевой акт предписания имеет предварительное условие, а именно, адресат данного речевого акта желает совершить конкретное действие, но определенные правила требуют от адресата получение «санкции» адресанта на совершение данного действия.

Нами рассматриваются директивные речевые акты предписаний (разрешений) и запретов, функционирующие в религиозном дискурсе. Отметим, что религиозный дискурс, с одной стороны, представляет собой один из типов институционального общения, с другой стороны, данный тип дискурса личностно-ориентирован. Кроме того, религиозный дискурс имеет ярко выраженную дидактическую направленность, как следствие, многие его текстовые образцы отличаются назидательностью. Указанные особенности, безусловно, накладывают отпечаток на предписания (разрешения) и запреты, функционирующие в данном типе институциональной коммуникации.

Понятия предписания (разрешения) и запрета напрямую связано с понятием нормы. Нормы и правила, функционирующие в конкретном обществе, или «социальные нормативные регуляторы» могут быть разрешительными и запретительными. Норма есть предписание «должного»; она описывает ситуацию, которая должна иметь место - идеальную ситуацию. В структуре любой культуры выделяется так называемая «нормативная культура», целью которой является установление норм и определение критериев правильного поведения человека.

Социальные нормы, действующие в обществе, классифицируются в зависимости от механизма формирования и способа обеспечения (защиты). Различают: 1) нормы морали правила поведения, установленные в соответствии с представлениями о добре и зле, справедливости и несправедливости, такие нормы охраняются силой общественного мнения; 2) нормы обычаев - правила поведения, сформированные в течение исторически длительного периода времени и вошедшие в привычку членов данного общества; 3) нормы общественных институтов - правила поведения, установленные и охраняемые определенным общественным институтом; 4) нормы права - правила поведения, установленные правовыми институтами данного общества; 5) религиозные нормы - правила поведения, установленные данным вероучением и используемые при совершении религиозных обрядов.

Религиозные нормы наиболее устойчивы. Они содержат «правильное» поведение, закрепленное в Священных книгах конкретной религии и регулируют отношения между людьми на основе определенных религиозных представлений. Соблюдение религиозных норм поддерживается религиозным сознанием верующих и страхом возможного наказания. Религиозные нормы закрепляют порядок богослужений, правила совершения религиозных обрядов (крещение, венчание и т.п.) и имеют авторитарный характер.

По мнению Н.В. Войченко, «а) религиозные нормы устанавливают тип отношения человека к религии, Богу, истине и окружающему миру; б) религиозные нормы закрепляют установленный порядок функционирования религиозных институтов; в) религиозные нормы регламентируют поведение и отношение между членами данного общества; г) религиозные нормы закрепляют порядок отправления религиозных обрядов; д) религиозные 
нормы обеспечиваются общественным мнением верующих и особыми санкциями, налагаемыми духовенством» [Войченко, 2019, с. 160]. С течением времени религиозные нормы могут приобрести юридическую силу и стать законами.

\section{Специфика религиозных предписаний (разрешений)}

Религиозные предписания (разрешения) представляют собой требования, которые передаются церковью (религиозными субъектами) от имени Бога или пророков. Подобные предписания регламентируют не только культовые действия, но и различные сферы человеческой жизни: бытовые, семейные вопросы, организацию трудовой деятельности и т.п.

Все религиозные предписания (разрешения) нам представляется возможным подразделить на два класса по цели и основному вектору направленности побуждения. С точки зрения адресантно-адресатных отношений религиозные предписания (разрешения) могут быть разделены таким образом: 1) предписания (разрешения), «порождаемые» Божественной силой и претендующие на статус «закона» для человека - их можно интерпретировать как «так положено», «так должно», «так следует» и они выступают именно в функции предписания: «...так действуйте в страхе Господнем, с верностью и с чистылм сердием: во всяком деле спорном, какое поступит квам от братьев ваших, живущих в городах своих, о кровопролитии ли, или о законе, заповеди, уставах и обрядах, наставляйте их, чтобы они не провинились пред Господом, и не было бы гнева [Его] на вас и на братьев ваших; так действуйте, - $и$ вы не погрешите»; 2) предписания, «порождаемые» Божественной силой как ответ на мольбы и просьбы человека - подобные предписания можно интерпретировать как разрешения - «можно» - «нельзя», «разрешено» - «запрещено»: «.... шесть дней можно делать дела, а в седьмой день суббота покоя, свя щенное собрание; никакого дела не делайте; это суббота Господня во всех жилищах ваших. В первый день да будет у вас священное собрание; никакой работы не работайте; и в течение семи дней приносите жертвы Господу; в седьмой день также священное собрание; никакой работы не работайте. Также в девятый [день] седьмого месяиа сего, день очищения, да будет у вас священное собрание; смиряйте души ваши и приносите жертву Господу» (Быт. 12. 3, 9).

Религиозные предписания различаются также по иллокутивной направленности и, соответственно, степени обязательности исполнения. Нами выделены побуждающие, рекомендательные, разрешающие, обязывающие, повелевающие и обещающие предписания.

1) Побуждающие предписания - предписания, в которых человека побуждают к совершению определенного действия, которое представляется необходимым с точки зрения установленного божественного закона: «...nлодитесь и размножайтесь, и наполняйте землю... и владычествуйте над рыбами морскими и над птицами небесными...» (Быт. 1. 28); «пойди из земли твоей, от родства твоего и из дома отца твоего, в землю, которую Я укажу тебе» (Быт. 12. 1).

2) Рекомендательные предписания - предписания, в которых человеку даются рекомендации по поводу того, как ему следует поступать: «Соблюдайте постановления мои, чтобы не поступать по гнусным обычаям, по которым поступали прежде вас, и чтобы не оскверняться ими»; «и пусть возьмут тельца и хлебное приношение к нему, пшеничной муки, смешанной с елеем, и другого тельиа возьми в жертву за грех» (Левит, 18. 30).

3) Разрешающие предписания - предписания, в которых одновременно содержится предписание и дается санкция человеку на совершение определенного действия: «странствуй по сей земле, и Я буду с тобою и благословлю тебя, ибо тебе и потомству твоему дам все земли сии и исполню клятву, которою Я клялся Аврааму, отиу твоему» (Быт. 26. 3, 5).

4) Обязывающие предписания - в предписаниях подобного рода человеку не просто предписывается совершить то или иное действие, но и постулируется, что по определенным причинам он должен это совершить: «Потому оставит человек отиа своего $u$ 
мать свою и прилепится к жене своей; и будут одна плоть», «Храните сие, как закон для себя и для сынов своих на веки» (Ефес. 5. 31).

5) Повелевающие предписания - предписания, включающие повеления человеку поступать определенным образом: «Встань, пойди в Месопотамию, в дом Вафуила, отия матери твоей, и возьми себе жену оттуда, из дочерей Лавана, брата матери твоей»; «Кто ударит человека так, что он умрёт, да будет предан смерти; но если кто не злоумышиял, а Бог попустил ему попасть под руки его, то Я назначу у тебя место, куда убежать [убийце]; а если кто с намерением умертвит ближнего коварно, то [и] от жертвенника Моего бери его на смерть. Кто ударит отца своего, или свою мать, того должно предать смерти. Кто украдёт человека и продаст его, или найдётся он в руках у него, то должно предать его смерти. Кто злословит отца своего, или свою мать, того должно предать смерти» (Исход, 21. 12, 17); «Субботь Мои соблюдайте и святилище Моё чтите: Я Господь» (Левит, 26. 2).

6) Обещающие предписания - в обещающих предписаниях человеку дается наставление поступать определенным образом и содержится обещание того, что он получит при условии выполнения определенных положений: «Исполняйте постановления Мои, и храните законы Мои и исполняйте их, и будете жить спокойно на земле» (Левит, 25. 17).

\section{Специфика религиозных запретов}

Религиозные запреты, также как предписания (разрешения) относятся к числу директивных (побудительных) высказываний. Многие исследователи рассматривают запрет в качестве «подтипа прескриптива, выражающего запрет в отношении чего-либо и представляющий по сути отрицательный приказ» [Руссинова, 2006, с. 14].

По мнению Я.В. Боргер, «речевой акт запрета выступает в качестве речевого акта негативной реакции, совмещающего в себе побуждение и запрет, при котором говорящий не разрешает совершать либо требует прекратить уже начатое к моменту речи действие (вербальное или невербальное)» [Боргер, 2004, с. 11].

Е.И. Беляева трактует запрет через приказ, определяя запрет как негативный приказ. Исследователь считает, что запрет есть «превентивный речевой акт, базирующийся на пресуппозиции наличия у адресата желания совершить некоторое действие, которое является нежелательным для говорящего» [Беляева, 1988, с. 17].

В.И. Карасик [2002] выделяет статустно-маркированные (приказы, требования, просьбы, мольбы) и статусно-нейтральные речевые акты (утверждения, повествования, описания), предписания и запреты, хотя в некоторых ситуациях возможность вынесения запрета не коррелирует со статусом коммуниканта и запрет может исходить от лица, имеющего как более высокий, так и низкий статус.

Однако чаще всего речевой акт запрета имеет место либо в ситуации, когда адресант, выносящий запрет, имеет более высокий социальный или возрастной статус, либо в ситуации равенства коммуникантов. В ситуациях социального или возрастного неравенства запрет может видоизменяться и принимать форму совета, предложения, пожелания и т.п. - для обеспечения успешности и бесконфликтности общения.

В любом случае общим признаком предписания (разрешения) и запрета выступает авторитарная позиция говорящего, позволяющая ему выносить предписание (разрешение) или ограничивать деятельность адресата (запрет).

Когнитивными признаками запрета являются категоричная форма, в которую облечено побуждение совершить конкретное действие; облигаторность выполнения данного действия для адресата; более высокий статус адресанта; бенефактивность действия для адресанта.

Директивный акт запрета, как правило, реализуется в прямой форме (в отличие от других речевых актов). Запрет является одним из подвидов директивного акта требования 
и, выступая видом требования, неоднороден по своему содержанию. Подобная неоднородность проявляется, прежде всего, в отношении времени, к которому относится запрещаемое действие. Могут быть выделены запреты-прескриптивы (превентивы) и запретыпрерывания. Если проанализировать запрет-прескриптив и запрет-превентив с точки зрения условий успешности речевого акта (выделенных Дж. Серлем), то можно отметить, что условия искренности обоих видов запретов совпадают: порождая и запрет-прескриптив, и запрет-превентив, говорящий выражает уверенность в необходимости того, чтобы действие не совершалось. Таким образом адресант считает необходимым запретить определенное действие, поскольку оно, по его мнению, не соответствует нормам поведения, веры, морали и т.П., а, соответственно, может принести вред человеку.

Но подготовительные условия запрета-прескриптива и запрета-превентива различны: в случае запрета-превентива действие происходило или человек планировал его совершить; в случае запрета-прескриптива говорящий пытается предотвратить совершение действия, поскольку оно по определенным причинам нежелательно, запретно и т.п. В обоих случаях адресант считает возможным нарушить планы адресата, запретив ему совершить данное действие. Запрет-превентив может быть отнесен к реактивным речевым актам, а запрет-прескриптив совмещает в себе черты инициативного и реактивного речевых актов, поскольку, с одной стороны, запрет выступает в качестве реакции на возможные действия, поведения и мысли собеседника или на ситуацию в целом, с другой стороны, является инициативным актом, потому что порождается до совершения определенного действия (вербального или невербального).

Речевой акт запрета никогда не выступает конечным актом (речевым или поведенческим). Далее может следовать объяснение причин, по которым адресант запрещает адресату совершить или предписывает ему не совершать чего-либо, а также определенные действия адресата (соблюдение или не соблюдение запрета).

Интересно и временное отнесение запрета-прескриптива и запрета-прерывания. Запрет-прерывание относится к прошлому или настоящему. Таким образом такие запреты распадаются на два подтипа в соответствии со временем прерывания действия - недавнее прошлое и настоящее. Запрет-превентив, как правило, относится к будущему. Подобный запрет обычно содержит предостережения от нежелательных последствий, которые подразумеваются ситуацией. В некоторых случаях запрет-превентив приобретает характер инструкции.

Любая религиозная система, в том числе и христианство, строится как четкая система правил, норм и предписаний, по которым должен жить человек. С другой стороны, христианское вероучение устанавливает целый ряд запретов, пытаясь не дать человеку совершить определенные нежелательные поступки. На протяжении тысячелетий христианство выработало систему предписаний (разрешений) и запретов, в рамках которых может действовать человек.

В наиболее общем виде (с теологической точки зрения нравственности и обязательности соблюдения) все запреты, функционирующие в рамках христианского вероучения, представляется возможным разделить на следующие:

- жесткие (полные) запреты - нормативные положения, налагающие полное ограничение на совершение определенных действий или определенное поведение (данные действия или поведения не допустимы ни при каких условиях и обстоятельствах);

- cuтуативные запреты (запреты средней степени жесткости) - нормативные положения, налагающие частичное ограничение на совершение определенных действий; определенное поведение или действия запрещены в данной ситуации, в данное время (ситуативно-временное ограничение);

- мягкие запреты - поучительные наставления, регулирующие поведение человека в различных ситуациях и имеющие форму совета или пожелания. 
Анализ структурно-семантических и прагматических характеристик запретов, функционирующих в религиозном дискурсе, позволил нам выделить следующие классы или категории запретов:

1) 3anpembl-законы. Закон в наиболее общем виде представляет собой нормативный акт, принимаемый в особом порядке и обладающий юридической силой. Сила «религиозного закона» увеличивается за счет того, что он исходит от Всевышнего и его нарушение несет более серьезные для человека последствия. Наказания за нарушение законов, установленных обществом, в некоторых ситуациях можно избежать, наказания же за нарушение законов, установленных Богом, избежать невозможно: «Не делай себе кумира и никакого изображения того, что на небе вверху и что на земле внизу, и что в водах ниже земли, не поклоняйся им и не служи им <...> Не произноси имени Господа, Бога твоего, напрасно; ибо не оставит Господь без наказания того, кто употребляет имя Его напрасно» (Исход, 20. 4).

2) 3aпреты-предписания. B наиболее общем виде предписание представляет собой «властное волеизлеяние уполномоченного субъекта, содержащее прямое указание о правилах поведения участников общественных отношений. Предписания выступают в двух видах: нормативном (следование нормам права) и индивидуально-персонифицированном (приговор, приказ лица, занимающего более высокое положение на социальной лестнице): «Не суди превратно тяжбы бедного твоего. Удаляйся от неправды и не умерщвляй невинного и правого, ибо Я не оправдаю беззаконника. Даров не принимай, ибо дары слепьми делают зрячих и превращзют дело правых» (Исход, 23. 7, 12).

3) Запреты-приказы. Любой приказ представляет собой правовой акт, инициируемый руководителем любого уровня, действующим на основе единоначалия, для решения задач, стоящих перед данной структурой (частью общества). Одним из центральных пунктов в данном определении является момент «единоначалия», который как раз четко прослеживается в приказе, исходящем от лица Всевышнего: «Не ешьте с кровью; не ворожите и не гадайте. Не стригите головы вашей кругом, и не порти края бороды твоей. Ради умершего не делайте нарезов на теле вашем и не накальвайте на себе письмен. Я Господь» (Левит, 19. 26)

4) Запреть-инструкции. Инструкция представляет собой свод правил, в котором прописывается пошаговая последовательность действий для получения требуемого результата, а также налагаются ограничения на совершение определенных действий. Ключевым моментом в данном определении выступает «пошаговость исполнения» и «налагаемые ограничения». Это то, что мы встречаем в религиозных запретах: адресант (Всевышний) не только налагает ограничения на совершение человеком определенных действий, но и комментирует то, как следует поступать, пошагово объясняя человеку, как ему стоит организовывать свою жизнь и какого поведения придерживаться: «И не берите выкупа за душу убийцы, который повинен смерти, но его должно предать смерти; и не берите выкупа за убежавшего в город убежища, чтоб ему [позволить] жить в земле [своей] прежде смерти [великого] священника. Не оскверняйте земли, на которой вы [будете жить]; ибо кровь оскверняет землю, и земля не иначе очищается от пролитой на ней крови, как кровью пролившего её. Не должно осквернять землю, на которой вы живёте, среди которой обитаю Я» (Чис. 35. 31).

5) Запреть-объяснения. Любое объяснение строится как набор утверждений, подтверждающих факты и уточняющих причины, суть и последствия принятия или непринятия какой-либо информации, а также верной или неверной интерпретации фактов. Объяснение может как разъяснять существующие положения, правила, законы, так и пытаться установить новые правила и законы. Часто объяснение сопровождается запросом понимания адресата информации, которую предоставляет ему адресант. Как правило, цель объяснения - попытаться ответить на вопросы «почему» и «как»: «не должен находиться у те- 
бя проводящий сына своего или дочь свою чрез огонь, прорицатель, гадатель, ворожея, чародей, обаятель, вызывающий духов, волшебник и вопрошающий мёртвых; ибо мерзок пред Господом всякий, делающий это, и за сии-то мерзости Господь Бог твой изгоняет их от лица твоего» (Второзак. 18. 10).

6) Запреты-требования. В наиболее общем виде требование представляет собой (речевое) действие, выраженное в настойчивой, категорической просьбе исполнить чтолибо: «Не обращайтесь к вызывающим мертвых, и к волшебникам не ходите, и не доводите себя до осквернения от них...» (Левит, 19. 31).

7) Запреты-просьбы. Выступая в роли запрета, просьба представляет собой мягкую форму реализации попытки запретить адресату выполнить определенное действие: «Без рассуждения не делай ничего, и когда сделаешь, не раскаивайся. Не ходи по пути, где развалины, чтобы не споткнуться о камень; не полагайся и на ровный путь; остерегайся даже детей твоих. Во всяком деле верь душе твоей: и это есть соблюдение заповедей. Верующий закону внимателен к заповедям, и надеющийся на Господа не потерпит вреда» (Сир. 32. 25).

\section{Заключение}

Все рассмотренные типы религиозных предписаний (разрешений) и запретов имеют различные (прямые и косвеннные) формы выражения, обладают различной иллокутивной силой и используются в различных ситуациях с различными целями. Побуждающие, рекомендательные, разрешающие, обязывающие, повелевающие и обещающие предписания (разрешения) имеют различную структуру и разную силу воздействия на адресата и выбираются адресантом в зависимости от ситуации общения. Разные типы запретов также предназначены для использования в разных ситуациях и с разными иллокутивными целями. Запреты-законы, запреты-приказы, запреты-требования, запреты-предписания и запреты-инструкции могут быть отнесены к жестким запретам, запреты-просьбы - к мягким, запреты-объяснения - к запретам ситуативным.

Перспективой проводимого исследования может стать рассмотрение особенностей функционирования предписаний (разрешений) и запретов в разных жанрах религиозного дискурса.

Выполненное исследование может быть использовано при проведении вузовского курса общего языкознания, во время лекционных и семинарских занятий по лексикологии и стилистике русского языка, в спецкурсах по теории текста и дискурса.

\section{Список литературы}

1. Аверьянова Е.В. 2015. Семиолингвистические аспекты православного и католического житийного дискурса XI-XVII веков (на материале церковнославянского и латинского языков). Дис.... докт. филол. наук. Тюмень, 379 с.

2. Арутюнова Н.Д. 1999. Язык и мир человека. М., Языки русской культуры, 896 с.

3. Беляева Е.И. 1988. Модальность и прагматические аспекты директивных речевых актов в современном английском языке. Дис. ... докт. филол. наук. М., 459 с.

4. Бикбаева Л.М. 2008.Система средств выражения побудительной модальности в татарском и русском языках. Автореф. дис. ... канд. филол. наук. Тобольск, 24 с.

5. Бобырева Е.В. 2007. Религиозный дискурс: ценности, жанры, стратегии (на материале православного вероучения). Волгоград, Научное издательство ВГСПУ «Перемена», 374 с.

6. Боргер Я.В. 2004. Комплексный анализ речевых актов негативной реакции (на материале современных драматических произведений). Автореф. дис. ... канд. филол. наук. Тюмень, 23 с.

7. Войченко Н.В. 2019. Аспекты взаимодействия религиозных и правовых норм. В кн. Развитие теории и практики управления социальными и экономическими системами. Материалы Восьмой международной научно-практической конференции, г. Петропавловск-Камчатский, 23- 
25 апреля 2019 года. Отв. за вып. Н.Г. Клочкова. Петропавловск-Камчатский, Издательство КамчатГТУ: 159-161.

8. Гудкова В.Б. 2003. Металингвистическое описание речевого акта в произведении художественной литературы: автореф... дис... канд. филол. наук. Самара. Самарский гос. пед. ун-т, 22 c.

9. Изитов А.И. 1998. Разрешение как побудительный речевой акт. В кн.: Язык, сознание, коммуникация. Вып. 5. Под ред. В.В. Красных, А.И. Изотова. М., Филология: 97-100.

10.Карасик В.И. 2002. Языковой круг: личность, концепты, дискурс. Волгоград, Научное издательство ВГСПУ «Перемена», 477 с.

11. Лобанова Е.В. 2011. Средства выражения побудительности в английском языке: когнитивно-онтологический подход. Автореф. дис. ... канд. филол. наук. Самара, 24 с.

12. Мечковская Н.Б. 1994. Социальная лингвистика. М., Аспект-Пресс, 207 с.

13. Руссинова Т.В. 2006. Особенности функционирования запрета: на материале русского и английского языков. Автореф. дис. ... канд. филол. наук. Саратов, 22 с.

14. Серль Дж.Р., Вандервекен Д. 1986. Основные понятия исчисления речевых актов. В кн.: Новое в зарубежной лингвистике. Вып. XVIII. Логический анализ естественного языка. Под ред. В.В. Петрова. М., Прогресс: 242-264.

15. Шатуновский И.Б. 2000. Речевые акты разрешения и запрещения в русском языке. В кн. Логический анализ языка. Языки этики. Под ред. Н.Д. Арутюновой и др. М., Языки русской культуры: 319-325.

16. Шмелев А.Д. 2004. Русский язык и внеязыковая действительность. Москва. Яз. славян. культуры, 492 с.

17. Skinner B.F. 1957. Verbal behavior. Acton, MA: Copley Publishing Group, 478 p.

\section{References}

1. Aver'yanova E.V. 2015. Semiolingvisticheskie aspekty pravoslavnogo i katolicheskogo zhitiynogo diskursa XI-XVII vekov (na materiale tserkovnoslavyanskogo i latinskogo yazykov) [Semilinguistic aspects of the Orthodox and Catholic hagiographic discourse of the XI-XVII centuries (based on the Church Slavonic and Latin languages)]. Dis.... doct. philol. sciences. Tyumen, $379 \mathrm{p.}$

2. Arutyunova N.D. 1999. Yazyk i mir cheloveka. [Language and the world of man]. Moscow, Publ. Yazyki russkoi kul'tury, 896 p.

3. Belyaeva E.I. 1988. Modal'nost' i pragmaticheskie aspekty direktivnykh rechevykh aktov v sovremennom angliyskom yazyke [Modality and pragmatic aspects of directive speech acts in modern English]. Dis.... doct. philol. sciences. M., 459 p.

4. Bikbaeva L.M. 2008. Sistema sredstv vyrazheniya pobuditel'noy modal'nosti v tatarskom i russkom yazykakh [The system of means of expressing incentive modality in the Tatar and Russian languages]. Abstract dis. ... cand. philol. sciences. Tobolsk, 24 p.

5. Bobyreva E.V. 2007. Religioznyy diskurs: tsennosti, zhanry, strategii (na materiale pravoslavnogo veroucheniya) [Religious discourse: values, genres, strategies (based on the Orthodox teaching)]. Volgograd, Publ. Nauchnoe izdatel'stvo VGSPU «Peremena», 374 p.

6. Borger Ya.V. 2004. Kompleksnyy analiz rechevykh aktov negativnoy re-aktsii (na materiale sovremennykh dramaticheskikh proizvedeniy) [Comprehensive analysis of speech acts of negative reaction (based on modern dramatic works)]. Abstract dis. ... cand. philol. sciences. Tyumen, 23 p.

7. Voychenko N.V. 2019. Aspekty vzaimodeystviya religioznykh i pravovykh norm [Aspects of the interaction of religious and legal norms]. In: Razvitie teorii i praktiki upravleniya sotsial'nymi i ekonomicheskimi sistemami [Development of theory and practice of management of social and economic systems]. Materials of the Eighth international scientific and practical conference, PetropavlovskKamchatsky, April 23-25, 2019. Resp. for issue: N.G. Klochkova. Petropavlovsk-Kamchatskiy, Publ. Izdatel'stvo KamchatGTU: 159-161.

8. Gudkova V.B. 2003. Metalingvisticheskoe opisanie rechevogo akta v proizvedenii khudozhestvennoi literatury: avtoref... dis... kand. filol. nauk. [Metalinguistic description of a speech act in a work of fiction: autoref ... dis ... Cand. Philol. sciences']. Samara. Publ. Samarskii gos. ped. un-t, 22 p.

9. Izitov A.I. 1998. Razreshenie kak pobuditel'nyy rechevoy akt [Permission as an incentive speech act]. In: Yazyk, soznanie, kommunikatsiya [Language, consciousness, communication]. Iss. 5. Eds. V.V. Krasnykh, A.I. Izotov. M., Publ. Filologiya: 97-100. 
10. Karasik V.I. 2002. Yazykovoy krug: lichnost', kontsepty, diskurs [Linguistic circle: personality, concepts, discourse]. Volgograd, Publ. Nauchnoe izdatel'stvo VGSPU «Peremena», 477 p.

11. Lobanova E.V. 2011. Sredstva vyrazheniya pobuditel'nosti v angliyskom yazyke: kognitivnoontologicheskiy podkhod [Means of expressing incentive in English: a cognitive-ontological approach]. Abstract dis. ... cand. philol. sciences. Samara, 24 p.

12. Mechkovskaya N.B. 1994. Sotsial'naya lingvistika [Social linguistics]. Moscow, Publ. Aspect Press, $207 \mathrm{p}$

13. Russinova T.V. 2006. Osobennosti funktsionirovaniya zapreta: na materiale russkogo i angliyskogo yazykov [Features of the functioning of the ban: on the material of the Russian and English languages]. Abstract dis. ... cand. philol. sciences. Saratov, 22 p.

14. Serl' Dzh.R., Vanderveken D. 1986. Osnovnye ponyatiya ischisleniya rechevykh aktov [Basic concepts of the calculus of speech acts]. In: Novoe v zarubezhnoy lingvistike [Basic concepts of the calculus of speech acts]. Iss. XVIII. Logicheskiy analiz estestvennogo yazyka [Logical analysis of natural language]. Ed. V.V. Petrova. M., Publ. Pgrogress: 242-264.

15. Shatunovskiy I.B. 2000. Rechevye akty razresheniya i zapreshcheniya v russkom yazyke [Speech acts of permission and prohibition in Russian]. In: Logicheskiy analiz yazyka. Yazyki etiki [Logical analysis of language. Languages of ethics]. Eds. N.D. Arutyunova et al. M., Publ. Yazyki russkoy kul'tury: 319-325.

16. Shmelev A.D. 2004. Russkii yazyk i vneyazykovaya deistvitel'nost' [Russian language and non-linguistic reality]. Moscow. Publ. Yaz. slavyan. kul'tury, $492 \mathrm{p}$

17. Skinner B.F. 1957. Verbal behavior. Acton, MA: Copley Publishing Group, 478 p.

\section{ИНФОРМАЦИЯ ОБ АВТОРЕ}

Омельченко Оксана Владимировна, преподаватель иностранного языка Волгоградского экономико-технического колледжа, г. Волгоград, Россия

\section{INFORMATION ABOUT THE AUTHOR}

Oksana V. Omelchenko, foreign language teacher, Volgograd College of Economics and Technology, Volgograd, Russia 